\title{
Espermatogênese de catetos (Tayassu tajacu)
}

[Spermatogenesis in the collared peccary (Tayassu tajacu)]

\author{
D.S. Costa ${ }^{1}$, M. Henry ${ }^{2}$, T.A.R. Paula ${ }^{3}$ \\ ${ }^{1}$ Universidade Estadual do Norte Fluminense \\ Laboratório de Sanidade Animal \\ Av. Alberto Lamego, 2000, Parque Califórnia \\ 28013-600 - Campos dos Goytacazes, RJ \\ ${ }^{2}$ Universidade Federal de Minas Gerais \\ ${ }^{3}$ Universidade Federal de Viçosa
}

\section{RESUMO}

Realizaram-se estudos morfológico e funcional da espermatogênese em 15 testículos de catetos adultos, provenientes de abatedouro comercial de animais silvestres. Foram estudados os estádios do ciclo do epitélio seminífero (CES), a população celular dos túbulos seminíferos, o rendimento intrínseco da espermatogênese, o índice das células de Sertoli, o diâmetro médio dos túbulos seminíferos e a proporção volumétrica dos componentes do parênquima testicular. $O$ coeficiente de eficiência de mitoses espermatogoniais foi de 22,54, a eficiência da mitose de 22,54, o rendimento meiótico de 1:2,7 e o rendimento geral da espermatogênese de 1:64. Concluiu-se que a espermatogênese dos catetos é muito semelhante à espermatogênese de suínos.

Palavras-chave: catetos, Tayassu tajacu, espermatogênese

\begin{abstract}
The aim of this study was to analyze morphologically and functionally the spermatogenesis in adult collared peccary. Fifteen testes provided by a commercial wild animal abattoir were used. The stages of the seminiferous epithelium cycle, the cellular number of the seminiferous tubules, the intrinsic efficiency of spermatogenesis, the Sertoli cells, the mean diameter of the seminiferous tubules and the volumetric proportion of testicular parenchyma components were analyzed. The mitosis efficiency coefficient in collared peccary was 22.54, the meiotic profile, 1:2.7, and spermatogenesis general profile was 1:64. It was concluded that spermatogenesis in peccary is very similar to that in pigs.
\end{abstract}

Keywords: peccary, Tayassu tajacu, spermatogenesis

\section{INTRODUÇÃO}

Os catetos (Tayassu tajacu) são animais gregários e rústicos que produzem carne e couro de excelente qualidade, para os quais existe grande demanda internacional. Membros da família Tayassuidae, os catetos se separaram da família Suidae há dezenas de milhões de anos (Bernirshchke, 1974). Contudo, apesar de serem bastante semelhantes ao porco doméstico e ao javali, os catetos não são porcos. A distribuição geográfica dos catetos é bastante ampla, sendo encontrados naturalmente na América do Sul, na América Central e no Sul dos Estados Unidos (Cabrera, Yepes, 1940). Em condições naturais, vivem em grupos de cinco a 15 indivíduos, constituídos por animais jovens e adultos de ambos os sexos (Ellison, Harwell, 1969). No

Recebido para publicação em 28 de janeiro de 2003

Recebido para publicação, após modificações, em 15 de setembro de 2003

E-mail: deiler@uenf.br 
Brasil, Miller (1930) relatou média de 12 indivíduos por grupo no Estado do Mato Grosso. Normalmente os grupos são estáveis e os seus membros nascem e permanecem no grupo até a morte (Nogueira Filho et al., 1999).

A espermatogênese é um processo sincrônico e regular de diferenciação celular pelo qual uma espermatogônia tronco é gradativamente diferenciada numa célula haplóide altamente especializada, o espermatozóide. Essa diferenciação envolve três classes de células germinativas: as espermatogônias, os espermatócitos e as espermátides. Esse processo, que ocorre nos túbulos seminíferos, dura em torno de 40 a 60 dias na maioria dos mamíferos estudados (França, Russell, 1998). Nos adultos, a espermatogênese é um processo contínuo que pode ser dividido em três fases distintas: a mitótica, a meiótica e a espermiogênese, cada uma caracterizada por mudanças morfológicas e bioquímicas dos componentes do citoplasma e núcleo celular (Courot et al., 1970). Apesar de já ser bem estudada em muitas espécies animais, a espermatogênese dos catetos ainda não tinha sido relatada, fato este que motivou a realização desta pesquisa.

\section{MATERIAL E MÉTODOS}

Utilizaram-se 15 catetos adultos, pesando em média $21,84 \pm 1,54 \mathrm{~kg}$, destinados ao abatedouro Pró-Fauna, localizado no município de Iguape SP. Imediatamente após o abate, os testículos foram colhidos e pesados depois de serem separados dos respectivos epidídimos. Em seguida, fragmentos do parênquima testicular foram imersos em solução de glutaraldeído e mantidos em geladeira até o processamento. $\mathrm{O}$ material coletado foi incluído em solução de glicol metacrilato, conforme técnica de rotina. Os cortes, de 4,0 $\mu \mathrm{m}$ de espessura, foram corados com solução de azul de toluidina - borato de sódio a $1 \%$.

Os estádios do ciclo do epitélio seminífero foram estudados pelo método da morfologia tubular (Curtis, 1918). As freqüências relativas, de cada um dos oito estádios do ciclo do epitélio seminífero, foram determinadas pela caracterização e contagem de, no mínimo, 200 secções de túbulos seminíferos, escolhidos ao acaso e percorrendo-se os cortes em varredura horizontal, conforme sugeriram Hess et al. (1990).

A população celular dos túbulos seminíferos foi estimada pela contagem dos núcleos dos diferentes tipos celulares da linhagem espermatogênica, assim como dos nucléolos das células de Sertoli. Cada tipo celular foi contado em pelo menos 20 secções transversais de túbulos no estádio 1 do ciclo do epitélio seminífero. Os seguintes tipos celulares foram contados: espermatogônias do tipo A (A), espermatócitos primários em pré-leptóteno/ leptóteno $(\mathrm{PL} / \mathrm{L})$, espermatócitos primários em paquíteno (PQ), espermátides arredondadas (Ar) e células de Sertoli (CS). A contagem obtida para cada tipo celular foi corrigida para o diâmetro nuclear médio e a espessura do corte, utilizandose a fórmula de Abercrombie (1946) modificada por Amann (1962).

O rendimento intrínseco da espermatogênese foi determinado baseando-se nas razões encontradas entre os números celulares corrigidos, obtidos no estádio 1 do ciclo do epitélio seminífero. As seguintes razões foram calculadas: coeficiente de eficiência de mitoses espermatogônias (PL/L:A), rendimento meiótico (Ar:PQ), rendimento geral da espermatogênese (Ar:A) e ocorrência de perdas celulares durante a prófase meiótica (PL/L:PQ).

O estudo das razões entre números de células da linhagem espermatogênica e de células de Sertoli no estádio 1 do ciclo do epitélio seminífero, ou seja, o índice de célula de Sertoli, abrangeu as razões que se seguem: A:CS, PL/L:CS, PQ:CS, $\mathrm{AR}: \mathrm{CS}$ e total de células germinativas:CS.

O diâmetro médio dos túbulos seminíferos foi obtido a partir da medida do diâmetro de 20 secções transversais de túbulos em cada testículo, independente do estádio em que se encontravam. As mensurações foram feitas com o auxílio de ocular micrométrica $10 x$ e objetiva de 10x. Na mesma secção em que se obteve o diâmetro tubular, também foi medida a altura do epitélio seminífero, considerando-se desde a membrana basal até a borda luminal. Duas anotações foram obtidas de cada secção transversal, considerando-se como medida representativa a média das duas. 
O comprimento total dos túbulos seminíferos foi calculado segundo Attal e Courot (1963). Considerou-se um fator de retração linear de 5\%, conforme Amann (1981).

\section{RESULTADOS E DISCUSSÃO}

O diâmetro tubular médio dos catetos (Tab. 1) encontra-se dentro dos valores considerados típicos para a maioria dos amniotas, que varia de 180 a $300 \mu \mathrm{m}$ (Roosen-Runge, 1977). A altura do epitélio seminífero insere-se dentro do intervalo relatado para os animais domésticos, 60 a $100 \mu \mathrm{m}$ (França, Russell, 1998). Apesar da grande variação dessa característica entre espécies, isso não se repete entre os estádios do ciclo do epitélio seminífero, a despeito das diferentes associações celulares e dos diferentes volumes de células de Sertoli em cada estádio (Wrobel, Schimmel, 1989).

Tabela 1. Diâmetro tubular e altura do epitélio seminífero de catetos adultos

\begin{tabular}{lcc}
\hline Animal & $\begin{array}{c}\text { Diâmetro do túbulo } \\
\text { seminífero }(\mu \mathrm{m})\end{array}$ & $\begin{array}{c}\text { Altura do epitélio } \\
\text { seminífero }(\mu \mathrm{m})\end{array}$ \\
\hline 01 & 289,88 & 71,16 \\
02 & 284,12 & 67,50 \\
03 & 278,00 & 67,20 \\
04 & 268,43 & 63,84 \\
05 & 300,34 & 66,98 \\
06 & 275,23 & 69,59 \\
07 & 289,36 & 67,50 \\
08 & 305,05 & 69,59 \\
09 & 265,81 & 59,65 \\
10 & 249,07 & 63,31 \\
11 & 265,81 & 60,17 \\
12 & 304,00 & 75,87 \\
13 & 280,46 & 67,50 \\
14 & 266,33 & 55,46 \\
15 & 262,15 & 69,59 \\
Média \pm SD & $278,94 \pm 16,54$ & $66,33 \pm 5,12$ \\
\hline
\end{tabular}

A maioria dos mamíferos apresenta de 10 a $15 \mathrm{~m}$ de túbulos seminíferos por grama de testículo (França, Russell, 1998). O comprimento tubular por testículo de catetos foi de $224,00 \pm 48,45 \mathrm{~m}$ e o comprimento tubular por grama de testículo foi de $10,33 \pm 1,35 \mathrm{~m}$, resultados semelhantes aos observados em suínos (França, 1991; Okwun et al., 1996) e nos queixadas (Paula, Navarro, 2001).

Baseando-se na morfologia nuclear e posição topográfica em relação a outras células e à lâmina basal, identificaram-se três tipos de espermatogônias em catetos: tipo A, intermediária e tipo B. A morfologia dessas células, dos espermatócitos primários em prófase meiótica, dos espermatócitos secundários e das espermátides dos catetos não diferiram substancialmente do descrito nos mamíferos em geral (Courot et al., 1970; Ortavant et al., 1977). Os diâmetros nucleares médios foram próximos aos descritos para suínos (Swierstra, 1968; França, 1991).

Foi possível identificar associações celulares típicas dos oito estádios do ciclo do epitélio seminífero. A exemplo da maioria dos mamíferos, as secções transversais de túbulos seminíferos dos catetos apresentam um único estádio do ciclo, em contraste com o observado em primatas, onde uma única secção transversal é ocupada por vários estádios (Clermont, 1963). Os oito estádios do ciclo do epitélio seminífero assemelham-se, em termos de composição celular, aos descritos em suínos (Swierstra, 1968; França, 1991), exceto pelo fato de que nesses últimos os espermatócitos I em zigóteno são encontrados nos estádios dois, três e quatro, e no estádio cinco, já se encontram na fase de paquíteno. Nos catetos, os espermatócitos I em zigóteno são encontrados nos estádios dois a cinco e apenas no estádio seis é que entram na fase de paquíteno da primeira prófase meiótica.

As freqüências relativas dos estádios do ciclo do epitélio seminífero são apresentadas na Tab. 2 . Os estádios 1 e 3 apresentaram, respectivamente, a maior e a menor freqüências. Comparações de freqüência relativa dos estádios entre espécies diferentes devem ser feitas com restrição, dada à grande variação de resultados.

Tabela 2. Freqüência relativa (\%) dos estádios do ciclo do epitélio seminífero de catetos adultos

\begin{tabular}{cccccccc}
\hline \multicolumn{7}{c}{ Estádios do ciclo do epitélio seminífero } \\
1 & 2 & 3 & 4 & 5 & 6 & 7 & 8 \\
\hline $21,69 \pm 4,21$ & $14,90 \pm 3,33$ & $6,35 \pm 2,92$ & $11,06 \pm 2,84$ & $7,31 \pm 2,94$ & $15,09 \pm 4,28$ & $9,19 \pm 1,31$ & $14,28 \pm 3,70$ \\
\hline
\end{tabular}


Na Tab. 3 são apresentados os números médios brutos e corrigidos de células espermatogênicas e de Sertoli observadas em secções transversais de túbulos seminíferos no estádio 1 do ciclo do epitélio seminífero de catetos. Os números celulares foram corrigidos dada à grande variabilidade que ocorre entre as espécies e entre indivíduos dentro de uma mesma espécie, quando os valores absolutos são comparados (Cardoso, 1981).

Tabela. 3. População dos diferentes tipos celulares no estádio 1 do ciclo do epitélio seminífero de catetos adultos

\begin{tabular}{lcc}
\hline Tipo celular & não corrigido & corrigido* \\
\hline Espermatogônias A & $2,09 \pm 0,36$ & $1,14 \pm 0,20$ \\
Espermatócitos I em pré-leptóteno/ leptóteno & $42,00 \pm 6,91$ & $25,70 \pm 4,23$ \\
Espermatócitos I em paquíteno & $54,04 \pm 9,15$ & $26,57 \pm 4,50$ \\
Espermátides arredondadas & $113,64 \pm 16,34$ & $72,96 \pm 10,49$ \\
Células de Sertoli & $7,61 \pm 1,14$ & $6,05 \pm 0,91$ \\
\hline *Valores corrigidos segundo Amann (1962) & &
\end{tabular}

*Valores corrigidos segundo Amann (1962)

O número médio de espermatogônias A foi próximo ao obtido para suínos das raças Yorkshire e Piau (Wettermann, Desjardins, 1979; França, 1991) e praticamente a metade do valor relatado para touros zebu (Cardoso, 1981). O número de espermatócitos I em préleptóteno/leptóteno e paquíteno, apesar de se aproximar dos valores encontrados para varrões Yorkshire (Wettermann, Desjardins, 1979), foi cerca de $50 \%$ do valor relatado para varrões Piau (França, 1991). Todavia, a constância do número de espermatócitos I durante a prófase meiótica, que é uma ocorrência generalizada nos mamíferos (Billaspuri, Guraya, 1986), também foi observada nos animais deste experimento.

A população de espermátides arredondadas em catetos é menor do que a relatada para suínos (Godinho, Cardoso, 1979; Wettermann, Desjardins, 1979; França, 1991) e praticamente o dobro da população observada em secções transversais de túbulos seminíferos de capivaras (Paula, 1999).

A partir do número médio corrigido de células de Sertoli por secção transversal de túbulo seminífero e do comprimento total destes túbulos, pode-se estimar a população total dessas células por testículo e por grama de parênquima testicular (Hochereau-De Rivers, Lincoln, 1978), tornando mais pertinentes as comparações entre espécies. Dessa forma, a população de células de Sertoli por testículo de catetos é da ordem de $339 \times 10^{6}$ células e a população de células de Sertoli por grama de parênquima testicular, em torno de $19 \times 10^{6}$ células. Esse último valor, apesar de ser semelhante ao encontrado em suínos (França, 1991) e capivaras (Paula, 1999), é mais baixo que o da maioria dos animais domésticos (França, Russell, 1998).

As razões numéricas entre espermatogônias A e os demais tipos celulares por secção transversal de túbulos constituem uma forma bastante acurada de se estimar o coeficiente de eficiência do processo espermatogênico. Isto permite comparações entre diferentes espécies, uma vez que é possível localizar as fases onde ocorrem perdas celulares e, inclusive, quantificá-las em termos percentuais (Russell et al., 1990).

O coeficiente de eficiência de mitoses espermatogoniais (razão entre espermatócitos I PL/L e espermatogônia A, no estádio 1) em catetos foi de 22,54 (Tab. 4), valor muito próximo ao citado para suínos Piau, 24,8 (França, 1991), e superiores aos valores relatados para a maioria dos animais domésticos (França, Russell, 1998).

Tabela 4. Razão entre números corrigidos de células germinativas por secção transversal de túbulo seminífero no estádio 1 do ciclo do epitélio seminífero de catetos adultos

\begin{tabular}{ll}
\hline Tipo celular & \multicolumn{1}{c}{ Razão } \\
\hline Espermatogônia A: Espermatócitos I PL/L & $1: 22,54$ \\
Espermatócitos I PL/L : Espermatócitos I PQ & $1: 1,03$ \\
Espermatócitos I PQ : Espermátides Ar & $1: 2,74$ \\
Espermatogônias A : Espermátides Ar & $1: 64,00$ \\
\hline
\end{tabular}

A população de espermatócitos I durante a prófase meiótica se manteve constante, como o referido para a grande maioria dos mamíferos (Billaspuri, Guraya, 1986). 
O rendimento meiótico (razão entre espermatócitos I PQ e espermátides Ar) foi de $1: 2,7$, equivalendo a uma perda de $32,5 \%$ de espermátides Ar quando se compara com a razão teórica esperada (1:4), caso o rendimento da espermatogênese fosse $100 \%$. Resultado semelhante foi encontrado em suínos adultos (França, 1991) e em várias espécies de animais domésticos (França, Russell, 1998).

Degenerações e mortes celulares na espermatogênese normal de mamíferos têm sido observadas por vários autores não só na fase de divisões meióticas como também durante a fase de proliferação espermatogonial (Billaspuri, Guraya, 1986). A ocorrência de apoptose pode ser um mecanismo para limitar o número de células germinativas a uma quantidade que pode ser suportada pelas células de Sertoli disponíveis (Sharpe, 1994). Dessa forma, mesmo em espécies com alta produção espermática, as perdas celulares durante as divisões espermatogoniais podem ser altas (Sharpe, 1994). A maior perda celular, na maioria dos mamíferos, ocorre durante a fase de divisões meióticas como um mecanismo de eliminação de células com cromossomos anormais ou aberrações (França, Russell, 1998). Normalmente essa perda é da ordem de $25 \%$ na maioria dos animais domésticos (França, Russell, 1998).

Seguindo as tendências até agora relatadas, o rendimento geral da espermatogênese (razão espermatogônias A: espermátides Ar) em catetos (Tab. 5) também foi equiparável ao relatado em suínos (Godinho, Cardoso, 1979; França, 1991). Os animais do presente experimento possuem rendimento geral da espermatogênese bem superior ao relatado para garanhões, 26,2, (Jones, Berndtson, 1986) e coelhos, 39,4, (Castro, 1995).

Tabela 5. Razão entre os números corrigidos de células germinativas, no estádio 1 do ciclo do epitélio seminífero, e de células de Sertoli (índice de célula de sertoli) em catetos adultos

\begin{tabular}{lc}
\hline \multicolumn{1}{c}{ Tipo celular } & Razão \\
\hline Células de Sertoli : Espermatogônias A & $1: 0,19$ \\
Células de Sertoli : Espermatócitos I PL/L & $1: 4,25$ \\
Células de Sertoli : Espermatócitos I PQ & $1: 4,39$ \\
Células de Sertoli : Espermátides Ar & $1: 12,01$ \\
Células de Sertoli : Total de células germinativas & $1: 20,89$ \\
\hline
\end{tabular}

A população de células de Sertoli permanece estável após a puberdade e ao longo dos diferentes estádios do ciclo (França, Russell, 1998). Dessa forma, as relações quantitativas entre estas células e as células da linhagem espermatogênica, conhecidas como índice de células de Sertoli, são utilizadas como parâmetros indicativos de eficiência de produção espermática e da capacidade de suporte de cada célula de sustentação no epitélio seminífero (Sharpe, 1994), sendo, portanto, o melhor reflexo da eficiência funcional das células de Sertoli (França, Russell, 1998). Segundo esses autores, o índice de células de Sertoli varia consideravelmente entre as espécies e, normalmente, quando a relação células de Sertoli:espermátides arredondadas é alta, a produção espermática diária também é alta, pois a habilidade das células de Sertoli em suportar espermátides é altamente correlacionada com a produção espermática diária por grama de testículo nestas espécies.

Encontraram-se $\quad 12,01 \quad$ espermátides arredondadas para cada célula de Sertoli. Este valor, apesar de semelhante ao encontrado em suínos Piau (França, 1991), é invariavelmente mais alto que os valores relatados para a maioria dos animais domésticos (França, Russell, 1998). $\mathrm{O}$ número total de células germinativas suportado por cada célula de Sertoli no estádio 1 do ciclo do epitélio seminífero foi semelhante ao observado em eqüinos e suínos (Jones, Berndtson, 1986; França 1991).

Segundo Russell et al. (1990), a eficiência da produção espermática é determinada pela menor proporção volumétrica das células de Sertoli em relação ao epitélio seminífero. Além da alta capacidade de suporte das células de Sertoli dos catetos, tal espécie ainda apresenta alta eficiência de produção espermática, uma vez que os animais deste experimento apresentam um dos mais baixos números de células de Sertoli por grama de testículo $\left(19 \times 10^{6}\right)$ e uma das mais altas proporções volumétricas de túbulo seminífero $(84,0 \%)$.

As razões entre os outros tipos de células germinativas e células de Sertoli seguem as mesmas proporções observadas por França (1991) em suínos Piau adultos. 


\section{Espermatogênese de catetos (Tayassu tajacu)}

Concluiu-se que a espermatogênese dos catetos é muito semelhante à espermatogênese de suínos.

\section{REFERÊNCIAS BIBLIOGRÁFICAS}

ABERCROMBIE, M. Estimation of nuclear populations from microtome sections. Anat. Rec., v.94, p.238-248, 1946.

AMANN, R.P. A critical review of methods for evaluation of spermatogenesis from seminal characteristics. J. Androl., v.2, p.37-58, 1981 .

AMANN, R.P. Reproductive capacity of dairy bulls. IV Spermatogenesis and testicular germ cell degeneration. Am. J. Anat., v.110, p.69-78, 1962.

ATTAL, J.; COUROT, M. Développement testiculaire et établissement de la spermatogénèse chez le taureau. Ann Biol. Anim. Bioch. Biophys., v.3, p.219- 241, 1963.

BENIRSHCHKE, K. Quest for the giant peccary: the chaco revisited. Zoonozis, v.25, p.364-372, 1974

BILASPURI, G.S.; GURAYA, S.S. The seminiferous epithelial cycle and spermatogenesis in rams (Ovis aries). Theriogenology, v.25, p.485-505, 1986.

CABRERA, A.; YEPES, J. Historia natural ediar: mamiferos sud-americanos. Buenos Aires: Cia. Argentina de Editores, $1940.370 \mathrm{p}$

CARDOSO, F.M. Morfologia, cinética e quantificação da espermatogênese em zebus (Bos indicus). 1981. 208f. Tese (Doutorado em Morfologia). Instituto de Ciências Biológicas, Universidade Federal de Minas Gerais, Belo Horizonte.

CASTRO, A.C.S. A proposed acrossomal system for identifying stages of the cycle of the seminiferous epithelium and a model for the kinetics of spermatogenesis in the rabbit. 1995. 112f. Thesis (Ph D).University of New Hampshire, Durham.

CLERMONT, Y. The cycle of the seminiferous epithelium in man. Am. J. Anat., v.112, p.35-51, 1963.

COUROT, M.; HOCHEREAU-DE-REVIERS, M.T.; ORTAVANT, R. Spermatogenesis. In: JOHNSON, A.D.; GOMES, W.R.; VANDEMARK, N.L. (Eds.). The testis. New York: Academic Press, 1970. v.1, cap.6, p.339-432.

CURTIS, G.M. The morphology of the mammalian semiferous tubule. Am. J. Anat., v.24, p.339-394, 1918.

ELLISON, J.E.; HARWELL, F. Mobility and home range of collared peccary in southern texas. J. Wildl. Manag., v.33, p.425-427, 1969 .

FRANCA, L.R. Análise morfofuncional da espermatogênese de suínos adultos da raça Piau. 1991. 185f. Tese (Doutorado em Morfologia). Instituto de Ciências Biológicas, Universidade Federal de Minas Gerais, Belo Horizonte.

FRANÇA, L.R.; RUSSELL, L.D. The testis of domestic animals. In: REGADERA, J.; MARTINEZ-GARCIA, R. (Eds.) Male reproduction: A multidisciplinary overview. Madrid: Churchill Livingstone, 1998. p.197-219.

GODINHO, H.P.; CARDOSO, F.M.. Desenvolvimento sexual de porcos Yorkshire. II. Estabelecimento e evolução da espermatogênese. Arq. Esc. Vet. UFMG., v.31, p.351-361, 1979.

HESS, R.A.; SCHAEFFER, D.J.; EROSCHENKO, V.P. et al. Frequency of the seminiferous epithelium in the rat. Biol. Reprod., v.43, p.517-24, 1990.

HOCHEREAU-DE-RIVIERS, M.T.; LINCOLN, G.A. Seasonal variation in the histology of the testis of the red deer, Cervus elephus. J. Reprod. Fertil., v.54, p.209-213, 1978 .

JONES, L.S.; BERNDTSON, W.E. A quantitative study of sertoli cell and germ cell population as related to sexual development and aging in the stallion. Biol. Reprod., v.35, p.138-148, 1986 .

MILLER, E.W. Notes on some mammals of southern Mato Grosso, Brazil. J. Mamm., v.11, p.18, 1930.

NOGUEIRA FILHO, S.L.G.; NOGUEIRA, S.S.C.; SATO, T. Estrutura social de pecaris (Mammalia, Tayassuidae) em cativeiro. Rev. Ecolog., v.1, p.89-98, 1999.

OKWUN, O.E.; IGBOELI, G.; FORD, J.J. et al. Number and function of sertoli cells, number and yield of spermatogonia, and daily sperm production in three breeds of boar. $J$. Reprod. Fertil., v.107, p.137-149, 1996.

ORTAVANT, R.; COUROT, M.; HOCHEREAU-DEREVIERS, M.T. Spermatogenesis in domestic mammals. In: COLE, H.H.; CUPPS, P.T. (Eds.). Reproduction in domestic animals. 3.ed. New York: Academic Press, 1977. Cap.8, p.203-227.

PAUlA, T. A.R. Avaliação histológica e funcional do testículo de capivaras adultas (Hydrochoerus hydrochaeris). 1999. 84f. Tese (Doutorado). Instituto de Ciências Biológicas, Universidade Federal de Minas Gerais, Belo Horizonte.

PAULA, T.A.R.; NAVARRO, R.D. Componentes testiculares de queixada (Tayassu pecari) e cateto (Tayassu tajacu). Rev. Bras. Reprod. Anim., v.25, p.206-208, 2001.

ROOSEN-RUNGE, E.C. The process of spermatogenesis in animals. Cambridge: University Press, 1977.

RUSSELL, L.D.; ETTLIN, R.A.; SINHA-HIKIM, A.P. et al Histological and histopathological evaluation of the testis. Clearwater. Cache River, 1990. 286p.

SHARPE, R.M. Regulation of spermatogenesis. In. KNOBIL, E.; NEIL, J.D. (Eds.). The physiology of reproduction. 2.ed. New York: Raven Press, 1994. p.13631434.

SWIERSTRA, E.E. Cytology and duration of the cycle of the seminiferous epithelium of the boar: duration of spermatozoa transit through the epididymes. Anat. Rec., v.161, p.171-186, 1968.

WETTERMANN, R.P.; DESJARDINS, C. Testicular function in boars exposed to elevated ambient temperature. Biol. Reprod., v.20, p.235-241, 1979.

WROBEL, K.H.; SCHIMMEL, M. Morphology of the bovine sertoli cell during the spermatogenic cycle. Cell Tissue Res., v.257, p.93-103, 1989. 